Научная статья

УДК 34:616

DOI 10.18101/2658-4409-2021-2-20-25

\title{
НЕНАДЛЕЖАЩЕЕ ОКАЗАНИЕ МЕДИЦИНСКОЙ ПОМОЩИ: ПРОБЛЕМЫ ВЗАИМОДЕЙСТВИЯ СЛЕДСТВЕННЫХ ОРГАНОВ С МЕДИЦИНСКИМ СООБЩЕСТВОМ ${ }^{* 1}$
}

\author{
(C) Тугаринова Снежана Петровна \\ эксперт Медицинской палаты Республики Бурятия, \\ начальник юридической службы Республиканского перинатального центра \\ Министерства здравоохранения Республики Бурятия \\ Россия, г. Улан-Удэ, ул. Пирогова, 15 \\ snezha_tsp@mail.ru
}

\begin{abstract}
Аннотация. В работе поднимается актуальная для современной следственной практики по ятрогенным делам проблема взаимодействия следственных органов с медицинским сообществом. Так, предлагается со стороны медицинского сообщества содействие в выполнении неотложных процессуальных действий - получение медицинской документации и производство выемки. При этом рекомендуется установить регламент в проведении следственного действия с учетом интересов медицинского сообщества и охраны врачебной тайны, гарантированных федеральным законом. Далее в целях недопущения криминализации медицинской деятельности необходимо выработать единую правовую концепцию и нормативный подход к определению преступлений, связанных с оказанием медицинской помощи, отказавшись от использования термина «ятрогенные преступления».

Ключевые слова: ответственность медицинских работников, получение медицинской документации, производство выемки, постановление о выемке, сохранение врачебной тайны, медицинское сообщество, межведомственное соглашение, ятрогения, ятрогенные преступления.
\end{abstract}

\section{Для цитирования}

Тугаринова С. П. Ненадлежащее оказание медицинской помощи: проблемы взаимодействия следственных органов с медицинским сообществом // Вестник Бурятского государственного университета. Юриспруденция. 2021. Вып. 2. С. 20-25.

Председатель Следственного комитета (CK) России принял участие в VII съезде Союза медицинского сообщества «Национальная медицинская палата».

А. Бастрыкин отметил, что для всестороннего и объективного расследования таких дел «требуется постоянно совершенствовать взаимодействие по вопросам подготовки нормативных актов, регламентирующих правила и стандарты оказания медицинской помощи, а также использования всех имеющихся возможностей судебно-медицинской экспертизы, от которой в конечном итоге зависит исход всего дела». Глава ведомства напомнил о том, что в Следственном комитете уже

\footnotetext{
* Статья составлена по материалам доклада, подготовленного автором для участия в межрегиональной научно-практической конференции «Ответственность медицинских работников при оказании (неоказании) медицинской помощи», организованной юридическим факультетом БГУ с участием Следственного комитета России по Республике Бурятия и Министерством здравоохранения Республики Бурятия в ноябре 2019 г.
} 
С. П. Тугаринова. Ненадлежащее оказание медицинской помощи: проблемы взаимодействия следственных органов с медицинским сообществом

принят ряд мер, в том числе необходимость назначения экспертизы по уголовному делу не в медицинских учреждениях субъекта, где произошел тот или иной случай, а в другом регионе либо в Москве. Также следователям более широко необходимо применять комплексные экспертизы. Также А. Бастрыкин поддержал идею о закреплении в новом законопроекте, который готовится по инициативе медицинского сообщества, понятия врачебной ошибки.

Председатель СК России поблагодарил Л. Рошаля за содействие, в том числе при проведении личных приемов граждан, которые столкнулись с вопросами ненадлежащего оказания медицинской помощи. А. Бастрыкин предложил и на региональном уровне внедрить практику совместных приемов граждан сотрудниками Следственного комитета и представителями медицинского сообщества.

Подытоживая приведенные факты, А. Бастрыкин подчеркнул, что только в тесном взаимодействии возможно выработать взвешенные подходы к решению имеющихся проблем.

В случаях возбуждения уголовного дела следственные органы публикуют пресс-релиз на сайте Следственного комитета. Медицинская палата Республики Бурятия, представляя интересы медицинских работников, выразила свое мнение в пресс-релизе от апреля 2019 г. Указанная публикация содержала некорректную информацию: «Несмотря на ухудшающееся состояние здоровья, пациенту надлежащая медицинская помощь оказана не была, в результате чего ребенок впал в кому». Медицинской палатой была сделана публикация в опровержение: только по результатам расследования действиям медицинских работников может быть дана объективная правовая оценка. В отсутствие надлежащих доказательств отсутствуют законные основания для того, чтобы делать преждевременные выводы. Была инициирована рабочая встреча с пресс-службой Следственного комитета России по Республике Бурятия по вопросам взаимодействия. Обсуждались вопросы отдельных процессуальных действий: запрос на получение медицинской документации и производство выемки. В том случае, если должностному лицу, проводящему расследование, требуется информация из медицинских документов, которая представляет врачебную тайну, то он направляет мотивированный запрос, что соответствует требованиям ч. 4 ст. 13 Федерального закона от 21.11.2011 № 323-Ф3 «Об основах охраны здоровья граждан в Российской Федерации». Важно понимать следующий нюанс. Выемка производится только при условии, если для проведения расследования значение имеют сами документы, а не содержащаяся в них информация.

Комплексный анализ норм действующего законодательства позволяет сделать вывод, что на основании запроса следственных органов медицинские учреждения не обязаны предоставлять оригиналы медицинской документации, такая обязанность существует только при производстве выемки в соответствии с действующим законодательством.

В уголовном процессе правила изъятия любых документов, в том числе и медицинских, прописаны в ст. 183 УПК РФ. В соответствии с этой статьей выемка производится в отношении определенных документов и предметов, если они имеют значение для расследования и точно известно, где они находятся. Закон позволяет производить выемку медицинских документов, содержащих врачебную 
тайну только при наличии постановления о производстве выемки, судебного решения. Было достигнуто соглашение о предоставлении документов на основании постановления о выемке.

При этом порядок действий должностного лица следующий:

- сотрудник органа предварительного следствия обращается в медицинское учреждение;

- при обращении в медицинское учреждение им предъявляется постановление, в котором дается разрешение на производство выемки, а также служебное удостоверение;

- для проведения выемки приглашаются представитель медицинского учреждения и ответственный за хранение медицинской документации сотрудник;

- если есть возможность - привлекаются двое понятых для фиксации факта выемки;

- если понятых пригласить не представляется возможным - производится фото или видеозапись, которая фиксирует ход следственного действия;

- после окончания изьятия медицинской документации должен быть составлен протокол, который подписывается участвующими в следственном действии лицами в двух экземплярах;

- один экземпляр протокола выемки должен быть оставлен представителям медицинского учреждения;

- важно, чтобы в протоколе были подробно описаны изымаемые документы, перечислены их индивидуальные признаки и реквизиты.

После окончания этого следственного действия изъятые документы приобщаются в качестве доказательства к материалам уголовного дела. До окончания следствия все документы хранятся в уголовном деле, а после по запросу медицинского учреждения оригиналы или копии документов передаются обратно.

По итогам совместной встречи подготовлен проект соглашения о взаимодействии между Следственным комитетом и Медицинской палатой. Межведомственное взаимодействие сторон будет осуществляться в целях защиты прав человека в сфере охраны здоровья, обеспечения оказания гражданам качественной медицинской помощи.

Соглашение предусматривает следующие формы взаимодействия:

- предоставление в МП РБ сведений о жалобах на ненадлежащее оказание медицинской помощи для совместного рассмотрения жалоб, участие МП РБ в разрешении конфликтных ситуаций по жалобам на ненадлежащее оказание медицинской помощи;

- сообщение в МП РБ о всех случаях возбуждения уголовных дел в отношении медицинских работников в связи с ненадлежащим оказанием медицинской помощи (по статьям 118, 109, 124, 238, 293 УК РФ);

- в форме отказа от применения к медицинским работникам меры пресечения, предусмотренной пунктом 7 статьи 98 УПК РФ (заключение под стражу);

- оказание МП РБ консультаций следователям при формировании перечня вопросов для проведения судебно-медицинских экспертиз, экспертиз качества медицинской помощи, иных медицинских экспертиз при проведении следственными органами экспертиз на стадии досудебной проверки или следствия; 
С. П. Тугаринова. Ненадлежащее оказание медицинской помощи: проблемы взаимодействия следственных органов с медицинским сообществом

- оказание МП РБ помощи с выбором экспертной организации и/или специалистов-экспертов для проведения судебно-медицинских экспертиз, экспертиз качества медицинской помощи, иных медицинских экспертиз как в Республике Бурятия, так и за пределами Республики Бурятия (для соблюдения принципа экстерриториальности) по доследственым проверкам и уголовным делам в отношении медицинских работников в связи с ненадлежащим оказанием медицинской помощи;

- проведение совместных встреч, круглых столов, конференций представителей следственного управления и медицинского сообщества для информирования медицинских работников об обстоятельствах, являющихся основаниями для проведения проверок и возбуждения уголовных дел в отношении медицинских работников, а также для информирования следователей о нормативных документах, на основании которых оказывается медицинская помощь (о порядках, стандартах, клинических рекомендациях, их статусе и условиях применения), о структуре и организации системы здравоохранения, иных вопросах, позволяющих следователям составить представление о системе здравоохранения и условиях оказания медицинской помощи и медицинских услуг;

- в иных формах, направленных на достижение целей.

Следственные органы с точки зрения уголовно-правового закона, Федерального закона от 21.11.2011 № 323-Ф3 «Об основах охраны здоровья граждан в Российской Федерации» должны оценивать правомерность или неправомерность действий врача. Результат лечения может быть разным, это зависит от многих факторов, в том числе индивидуальных особенностей организма пациента. Оценка действий врача может быть только с точки зрения соблюдения требований о качестве медицинской помощи и ее своевременности, оценки факторов, повлиявших на невозможность соблюсти эти требования.

В последние несколько лет мы наблюдаем небывалую актуализацию темы ятрогении в контексте противоправного поведения медицинских работников. Проблема исследуется в средствах массовой информации, интервью, научных, научно-популярных работах, получила практическую реализацию в деятельности Следственного комитета РФ.

В Большой медицинской энциклопедии приводится термин «ятрогенный» (иатрогенный) (от греч. Iatros - врачи, gennao - произвожу), обозначающий отрицательное воздействие врача на больного, когда вместо терапевтического эффекта у больного создаются представления, усугубляющие его болезненное состояние, или образуется психологический комплекс новой болезни. Ятрогенное заболевание обычно диагносцируется при последующем обращении больного к другому врачу.

Надо отметить, что в результате совместной работы Главного управления криминалистики СК РФ и Союза медицинского сообщества «Национальная медицинская палата» над предложенной Следственным комитетом концепцией из проекта пояснительной записки был исключен термин «ятрогенные преступления», и обоснования необходимости реформирования УК РФ в части выделения специальных норм, предусматривающих ответственность медицинских работников, базируются на факте роста обращений граждан, сложности расследования такого 
рода преступлений и необходимости квалифицировать деяния в соответствии со статьями УК РФ, в полной мере не учитывающими специфику медицинской деятельности и особенностей расследования деяний в сфере оказания медицинской помощи, отсутствию единообразия судебной практики.

Тем не менее 26 ноября 2018 г. приказом Председателя СК РФ в СК РФ создаются отделения по расследованию ятрогенных преступлений. Сам факт создания специализированных отделений для расследования сложных уголовных дел не вызывает нарекания. Непонимание порождает стремление именовать новые структуры и отдельную группу деяний термином, не имеющим, как отмечалось выше, нормативной определенности по отношению к конкретным видам преступлений и субъектам этих деяний, но имеющим совершенно определенное медицинское и философское значение. Создавая дискурс в масштабе государства, стоит задуматься, не ведет ли он к дополнительной криминализации медицинской деятельности? Насколько оправдан такой поход?

При этом термин «ятрогенные осложнения» в нормативно-правовых актах Минздрава не раскрывается, употребление его происходит, например, для оценки внутреннего контроля соблюдения установленных порядков оказания медицинской помощи и стандартов медицинской помощи путем перечисления в ряду мер оценки качества медицинской помощи, таких как оптимальность выбора медицинских технологий с учетом минимизации риска их применения, принятие адекватных мер профилактики ятрогенных осложнений, соблюдение правил хранения и применения лекарственных препаратов, расходных материалов, обеспечение санитарно-гигиенического и противоэпидемического режимов в соответствии с санитарно-эпидемиологическими нормами и правилами и другими.

Согласно Международной классификации болезней - МКБ-10 (в РФ введена Приказом Минздрава РФ от 27.05.97 № 170) термин имеет расширенное толкование, под ятрогенией понимаются как любые нежелательные или неблагоприятные последствия профилактических, диагностических и лечебных вмешательств либо процедур, которые приводят к нарушениям функций организма, ограничению привычной деятельности, инвалидизации или смерти, так и осложнения медицинских мероприятий, развившиеся в результате как ошибочных, так и правильных действий врача.

Позиция Медицинской палаты в отношении вышеизложенного состоит в следующем: в целях предотвращения криминализации медицинской деятельности необходимо выработать единую правовую концепцию и нормативный подход к определению преступлений, связанных с оказанием медицинской помощи, исходя из действующих статей УК РФ, инкриминируемых медицинским работникам, отказавшись от использования термина «ятрогенные преступления».

Статья поступила в редакцию 15.04.2021; одобрена после рецензирования 18.05.2021; принята к публикачии 22.06.2021.

\section{Литература}

1. Леонтьев О. В., Тимофеев И. В. Медицинская ошибка. Медикоорганизационные и правовые аспекты. Санкт-Петербург : ДНК, 2002. 80 с. Текст : непосредственный. 
С. П. Тугаринова. Ненадлежащее оказание медицинской помощи: проблемы взаимодействия следственных органов с медицинским сообществом

2. Тимофеев И. В. Дефект медицинской помощи: проблемы и пути правовой формализации понятия // Медицинское право. 2018. № 6. С. 8-16. Текст : непосредственный.

\title{
INAPPROPRIATE MEDICAL CARE: PROBLEMS OF INTERACTION OF THE INVESTIGATIVE AUTHORITIES WITH THE MEDICAL COMMUNITY
}

\author{
Snezhana P. Tugarinova \\ Expert of Medical Association of the Republic of Buryatia, \\ Head of Legal Service of Republican Perinatal Center \\ under the Ministry of Health of the Republic of Buryatia \\ 15 Pirogova St., Ulan-Ude, Russia \\ snezha_tsp@mail.ru
}

Abstract. The article raises the problem of interaction of the investigating authorities with the medical community, which is relevant for modern investigative practice in iatrogenic cases. Thus, we recommend the medical community to assist investigative authorities in performing urgent procedural actions - obtaining medical records and execution of seizure. At the same time, it is offered to establish rules for investigative activities, taking into account the interests of the medical community and physician-patient privilege guaranteed by federal law. Further, in order to prevent the criminalization of medical activities, it is necessary to develop a unified legal conception and a regulatory approach to the definition of crimes related to medical care, and to abandon using the term «iatrogenic crime». Keywords: responsibility of medical professionals, obtaining medical records, execution of seizure, seizure order, physician-patient privilege, medical community, interdepartmental agreement, iatrogenesis, iatrogenic crime

\section{For citation}

Tugarinova S. P. Inappropriate Medical Care: Problems of Interaction of the Investigative Authorities with the Medical Community. Bulletin of Buryat State University. Law. 2021; 2: 20-25 (In Russ.).

The article was submitted 15.04.2021; approved after reviewing 18.05.2021; accepted for publication 22.06.2021. 